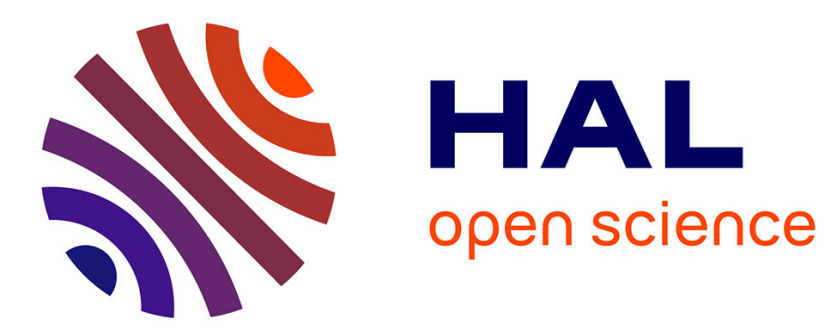

\title{
Study on plastic forming of metal alloys in partly-liquid state
}

\author{
W. Lapkowski, M. Pietrzyk, Z. Kedzierski
}

\section{To cite this version:}

W. Lapkowski, M. Pietrzyk, Z. Kedzierski. Study on plastic forming of metal alloys in partly-liquid state. Journal de Physique IV Proceedings, 1993, 03 (C7), pp.C7-829-C7-834. 10.1051/jp4:19937130 . jpa-00251750

\section{HAL Id: jpa-00251750 https://hal.science/jpa-00251750}

Submitted on 1 Jan 1993

HAL is a multi-disciplinary open access archive for the deposit and dissemination of scientific research documents, whether they are published or not. The documents may come from teaching and research institutions in France or abroad, or from public or private research centers.
L'archive ouverte pluridisciplinaire HAL, est destinée au dépôt et à la diffusion de documents scientifiques de niveau recherche, publiés ou non, émanant des établissements d'enseignement et de recherche français ou étrangers, des laboratoires publics ou privés. 


\title{
Study on plastic forming of metal alloys in partly-liquid state
}

\author{
W. LAPKOWSKI, M. PIETRZYK and Z. KEDZIERSKI
}

Akademia Gorniczo-Hutnicza, University of Mining and Metallurgy, Mickiewicza 30, 30-059 Krakow, Poland

\begin{abstract}
The paper presents a fragment of the work on the formability of alloys in the partly liquid state carried out at the University of Mining and Metallurgy in Krakow, Poland. The process of upsetting of cylindrical samples is investigated and the aluminum alloy 2024 (ASTM) of a relatively large crystallization temperature range is used as a testing material. The investigation focuses on the effect of the solid fraction (weight percentage of solid component in the alloy, pre-heated to the temperature above the solidus point) on the process parameters. Thermal-mechanical finite-element model developed for the compression test and adapted to the partly liquid conditions is used for the calculations of the distributions of strain rates, strains and temperatures. The micrographs of the samples after preheating and after deformation in both solid and partly liquid conditions are also presented in the paper.
\end{abstract}

\section{INTRODUCTION}

The plastic forming of metal alloys in partly liquid state is one of the latest methods in the forming of special metallic products. This process consists in the deformation of the material after it has been heated to a temperature exceeding the solidus point. In such conditions two phases, solid and liquid, coexist in the alloy and their mutual proportion in the entire volume of the material depends on the temperature. Because of the presence of the liquid component, a change in the mechanism of plastic deformation occurs and the conditions of metal flow are affected. In the temperature of the alloy above the solidus point, the liquid component appears at the grain boundaries and makes the plastic deformation to be mainly due to the effect of rotations and relative slip between the grains. The deformation of grains themselves has minor contribution to the metal flow in partly liquid state. It may be expected that such a mechanism of deformation makes the metal flow easier and leads to lower than in the conventional process resistance to deformation. Moreover, as it is shown in [1-4], the deformation of the partly liquid materials allows to improve the workability [5] and to manufacture products with the properties which cannot be obtained in conventional methods.

Earlier experimental investigations carried out for the $\mathrm{Al} 5.7 \% \mathrm{Cu}[6]$ and $\mathrm{Al} 13.7 \% \mathrm{Mg}$ [7] alloys confirm that deformation of the materials at the temperatures above their solidus point has several unusual advantageous features. A suggestion was made in [7] that the volume fraction of the solid phase is the factor which determines the flow pattern and material's properties. An attempt to generalize this suggestion and to improve the quality of the modelling of the materials in the partly liquid state is the prime objective of the present paper. A number of experiments, including the upsetting of the cylindrical specimens, has been carried out to generalize the problem. The aluminium alloy duralumin 2024 (ASTM) has been used as a testing material. The investigation focuses on the effect of the solid fraction (weight percentage of solid component in the alloy) on the process parameters. Thermal - mechanical finite element model developed for the compression process and adapted to the partly liquid conditions is used for the calculation of distributions of strain rates, strains and temperatures. The structures before and after deformation in various temperature conditions have also been investigated. 


\section{EXPERIMENT}

The aim of the experiment follows earlier investigations carried out for the aluminum-copper alloy [6] and aluminum-manganium alloy [7] and it focuses on the investigation of the possibility of plastic deformation of materials heated to the temperatures above the solidus point. The process of the compression of the axisymmetrical samples has been chosen and an analysis included flow pattern of the metal and force parameters. The material used in the present experiment is the aluminum based alloy containing $4.87 \% \mathrm{Cu}, 0.53 \% \mathrm{Mg}, 0.98 \% \mathrm{Mn}$ and $0.47 \% \mathrm{Si}$. This composition gives large interval between the liquidus and the solidus points $\Delta T_{c r}=T_{l}-T_{s}$ and creates very good conditions for an investigation of the deformation of the materials with various volume fraction of the liquid phase determined by the actual temperature of the alloy.

The critical temperature for the crystallization of the alloy has been determined analytically from the phase equilibrium diagram and experimentally from the liquidus curve of the alloy. The following values have been obtained for the investigated material: $T_{l}=640^{\circ} \mathrm{C}, T_{s}=510^{\circ} \mathrm{C}$ and $\Delta T_{c r}=130^{\circ} \mathrm{C}$. Thermal analysis of the alloy has been also used to determine the volume fraction of the solid phase [8] as a function of the temperature in the $\Delta T_{\mathrm{cr}}$ range and the results are compared with the earlier data for the AlCu and AlMg alloys in Fig.1.

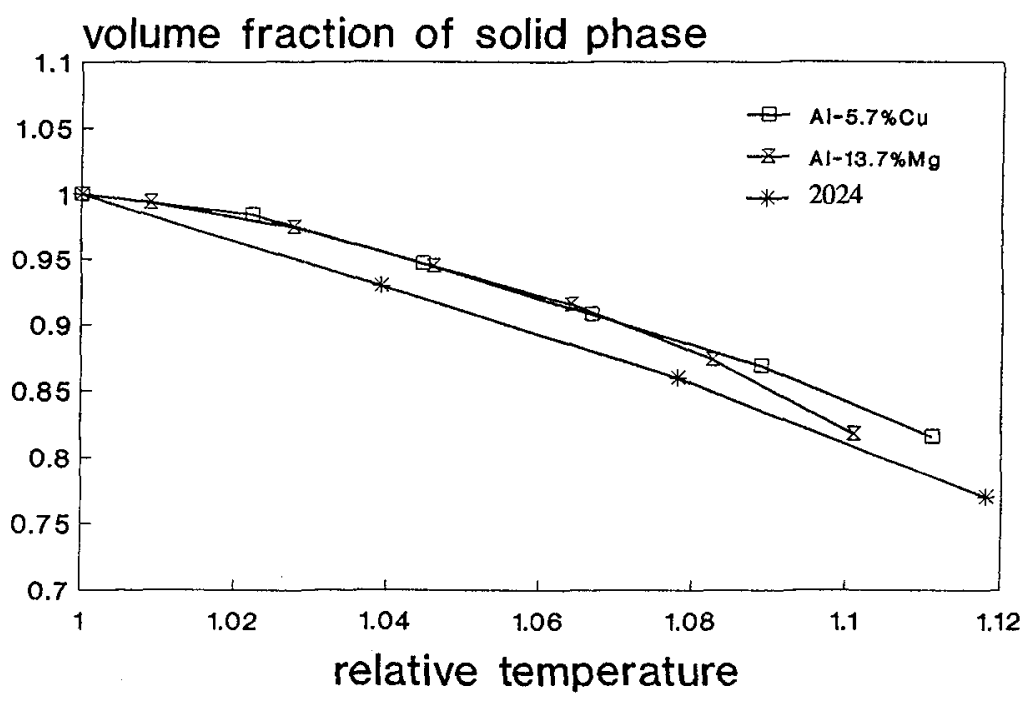

Fig.1. Volume fraction of the solid phase as a function of the temperature for $\mathrm{Al}-5.7 \% \mathrm{Cu}, \mathrm{Al}-13.7 \mathrm{Mg}$ and 2024 alloys.

Cylindrical samples measuring $\Phi 30 \times 45 \mathrm{~mm}$ have been machined from the extruded bars. In order to maintain centering of the process, conical marks have been done on the bottom surface of each sample. All samples have been annealed before the experiment. The microstructure of the sample before the deformation is shown in Fig.2. The intercrystalline phase particle are seen in this figure as bands parallel to the axis of the sample. The varying parameters in the experiment were the deformation temperature $T$ (which determines the volume fraction of the solid phase) and the relative reduction $\epsilon$. The experiment has been planned for the following values of these parameters:

-temperature of deformation

$T=430^{\circ} \mathrm{C}-510^{\circ} \mathrm{C}$ (conventional hot working, $\phi=1$ )

$T=530^{\circ} \mathrm{C}(\phi=0.93)$

$T=550^{\circ} \mathrm{C}(\phi=0.86)$

$T=570^{\circ} \mathrm{C}(\phi=0.77)$
- relative reduction (strain)

$\epsilon=0.1$, (reduction $\Delta h=4.5 \mathrm{~mm}$ )

$\epsilon=0.2$, (reduction $\Delta h=9.0 \mathrm{~mm}$ )

$\epsilon=0.3$, (reduction $\Delta h=13.5 \mathrm{~mm}$ )

$\epsilon=0.4$, (reduction $\Delta h=18.0 \mathrm{~mm}$ ) 
In all tests the average strain rate $\epsilon_{1}=1.85$ $10^{-3} \mathrm{~s}^{-1}$ has been maintained. The sensitivity of the 2024 alloy in the mushy state to the rate of deformation has been assessed on the basis of the data obtained for the AlCu alloy [6].

The measured values of the flow stress for 0.05 strain are presented in Fig.3 as a function of the temperature. A drop of the flow stress above the solidus point $\left(T_{s}=510^{\circ} \mathrm{C}\right)$ is well seen in this figure. The hypothetical values of the flow stress of the solid phase in the temperatures above the solidus point are shown by dotted line in Fig.3. This part of the curve has been obtained by an extrapolation of the flow stress curve below the solidus point. Comparison of the results presented in [7] with the curves in Fig. 3 allows to conclude that the contribution of the liquid phase to the decrease of the flow strength is smaller for the 2024 alloy than for the investigated earlie $\mathrm{AlCu}$ and $\mathrm{AlMg}$ alloys.

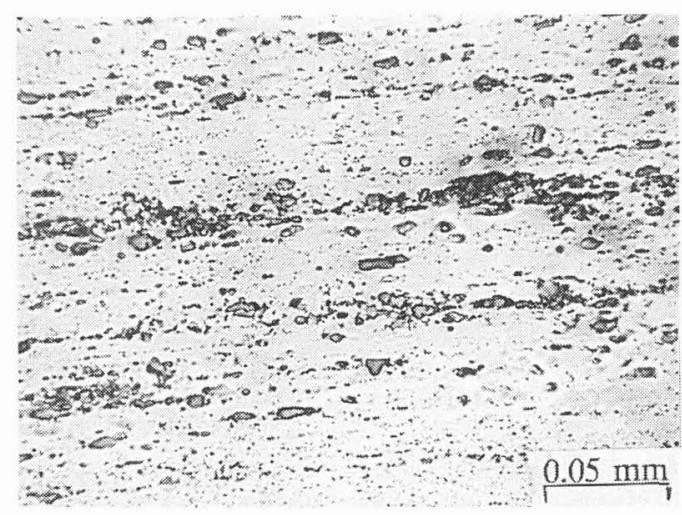

Fig.2. Microstructure of the 2024 alloy before the deformation.

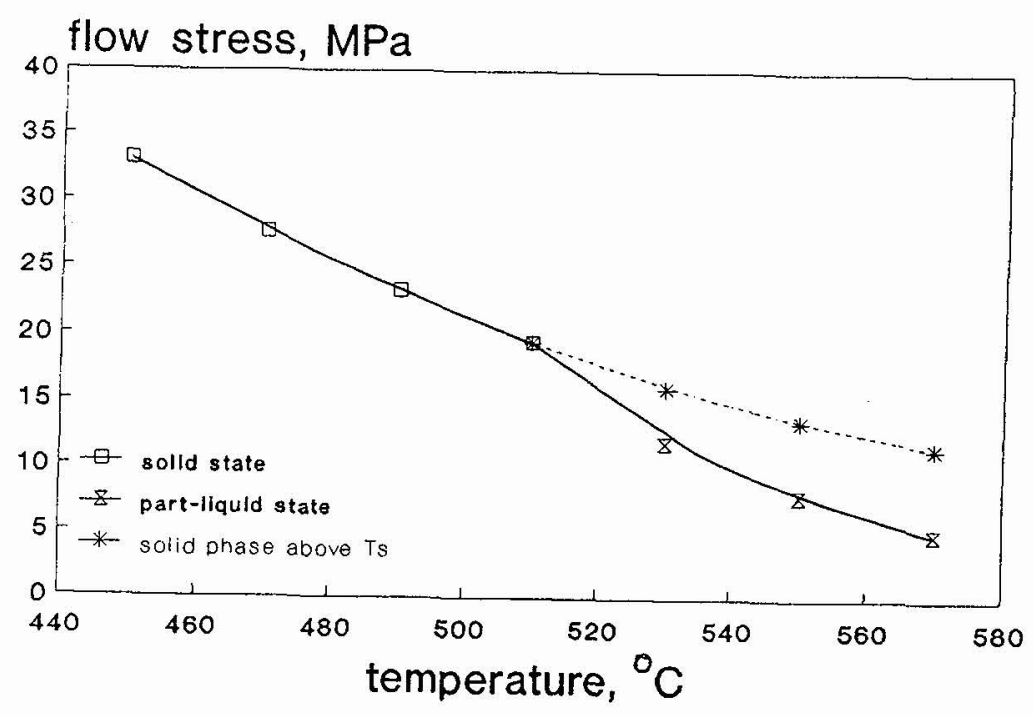

Fig.3. Flow stress vs. temperature of deformation for 2024 alloy.

\section{MATHEMATICAL MODEL}

Thermal-mechanical finite-element model developed for the axisymmetric compression $[9,10]$ is used here to simulate the deformation of partly liquid materials. The model consists of two parts, mechanical and thermal components. The mechanical component is based on the rigid-viscoplastic flow formulation. Thermal component determines the temperature field from the finite-element non-steady state solution of the general diffusion equation [9]. As it was shown in earlier publications $[6,7]$, the main difficulties in an application of the flow formulation to the partly liquid materials are connected with the evaluation of the yield criterion for the alloys in their mushy state. The objective of the present paper is to investigate further the model's predictive ability when the softening factor calculated as a function of the volume fraction of the liquid phase is introduced in the constitutive equations. The softening factor here $\bar{\sigma}$ is defined as a flow stress of the partly liquid material related to the hypothetical flow stress of the solid phase in the same temperature. The latter value is determined from the extrapolation curve marked by the dotted line in Fig.3. The softening factor determined 
experimentally for the $\mathrm{Al} 5.7 \% \mathrm{Cu}$ and $\mathrm{Al} 13.7 \% \mathrm{Mg}$ alloys in conjunction with the rigid-viscoplastic and strain hardening type equations gave very good coincidence between the theoretical and experimental data [7]. The question arises as to how far these conclusion drawn for two alloys can be generalized for other materials. Analysis of the flow stress vs. temperature curves presented in Fig. 3 shows that the softening effect of the liquid phase is smaller for the 2024 alloy than for the AlCu and AlMg alloys investigated earlier. Indeed, introduction of the softening function obtained in [7] led to significant discrepancies between the experimental data and the results of the calculations for the 2024 alloy. Approximation of the experimental data for this alloy allowed to derive the equation describing the softening factor for 2024 :

$$
\bar{\sigma}=(1+4 \phi)^{-1.726}
$$

In equation (1) $\phi$ is the volume fraction of the liquid phase and $\bar{\sigma}$ represents the softening factor which is dimensionless. As it is seen in [7], different equation describing softening factor gives good predictions of metal flow for the AlCu and AlMgalloys. Therefore, further investigation of this problem for other materials seems to be necessary. The equation (1) is introduced into the finite-element model and used in all further calculations presented in the next section.

\section{RESULTS}

The results of the calculations carried out using experimentally determined softening factor (equation (1)) are compared with the measurements of the stress-strain curves for various temperatures in Fig.4. It is seen that very good agreement between theoretical and experimental data exists. It may lead to a conclusion that an introduction of the experimentally determined solid state stress-strain curves and the softening factor into the finite-element program results in a good predictive ability of the model. On the other hand, an attempt of the generalization of the softening effect, by describing the softening factor as a function of the volume fraction of the liquid material only, failed for the 2024 alloy.

Microstructures of the samples after deformation in the solid and partly liquid states are presented in Figs 5 and 6. It is seen in Fig.5 that deformation below the solidus point leads to the precipitation of the dissolved intermetallic phases on the grain boundaries during cooling. Contrary, the eutectic is

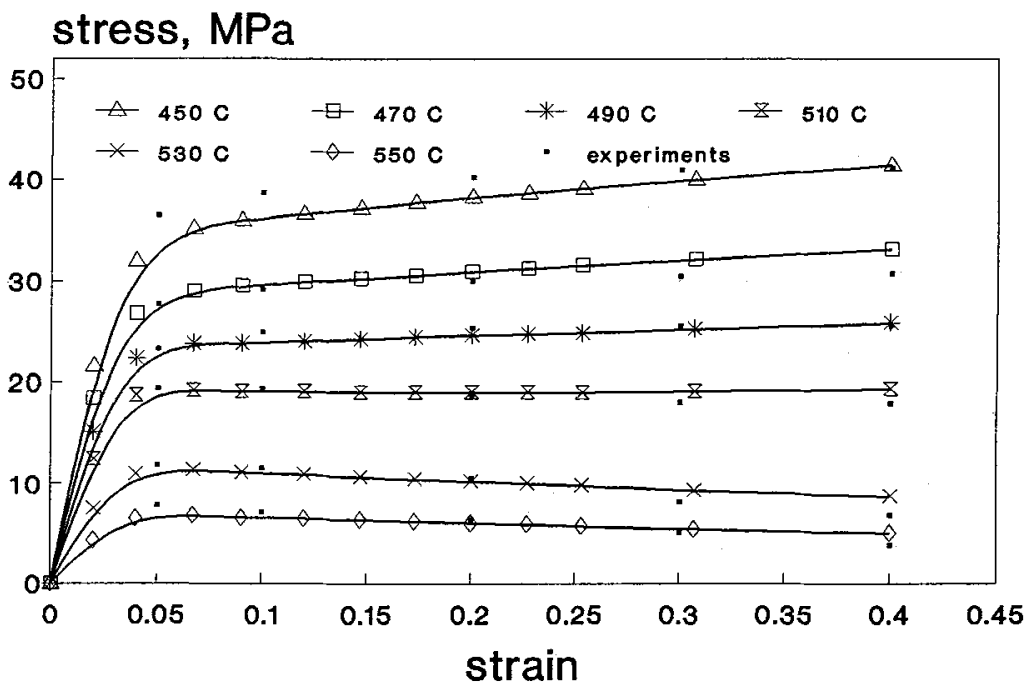

Fig.4. Comparison of measured and calculated stress-strain curves for various temperatures of deformation. 


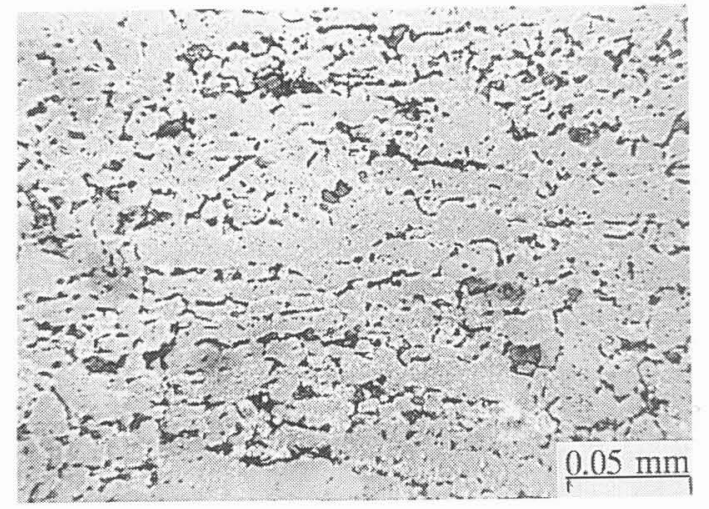

Fig.5. Microstructure of the 2024 alloy after deformation below the solidus temperature.

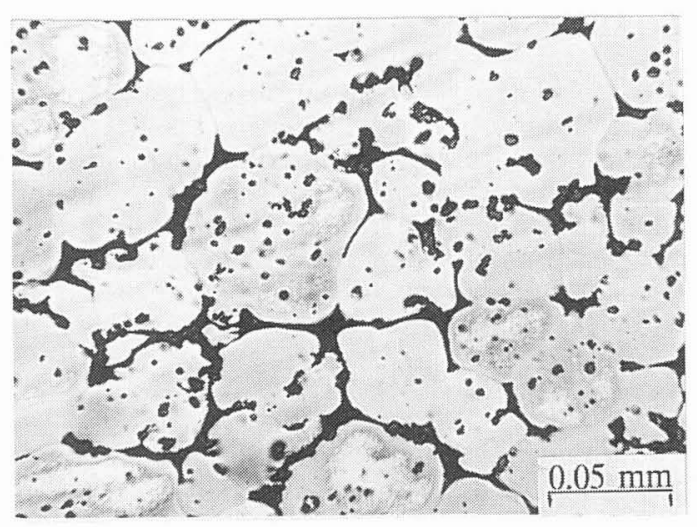

Fig.6. Microstructure of the 2024 alloy after deformation above the solidus temperature.

observed on the grain boundaries in the sample deformed above the solidus point (Fig.6). The liquid phase on the grain boundaries crystallized in the form of the eutectic during cooling after the deformation. This eutectic is formed in the areas where the liquid phase was present during the deformation.

Rigid-viscoplastic finite element model allows also the determination of the fields of strain rates, strains, stresses and temperatures in the deformation zone. The results obtained here for the 2024

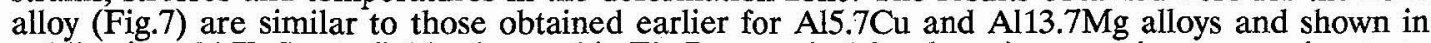
publications [6,7]. Strain fields observed in Fig.7 are typical for the axisymmetric compression tests. Analysis presented in [6] reveals also an important influence of the strain rate sensitivity of the part-liquid materials on the modelling of plastic deformation. Due to this strong viscoplastic effect the barreling phenomenon is insignificant in the considered cases. In the present work the rate sensitivity tests were performed for the partly liquid material only and the results were extended to the analysis of the solid material. In consequence, due to softening effect, the strain nonuniformity and barelling are more pronouced in the partly liquid material than in the solid state material. The problem of the rate sensitivity of the partly liquid alloys requires further investigation. Generalization of this problem on various alloys does not seem possible and, probably, strain rate sensitivity test would have to be performed for each investigated material.

a) sol (d ( $450 \mathrm{C})$

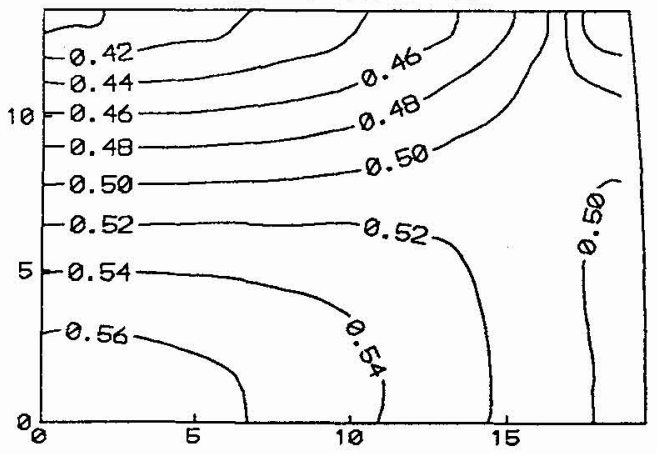

b) mushy ( $550 \mathrm{C})$

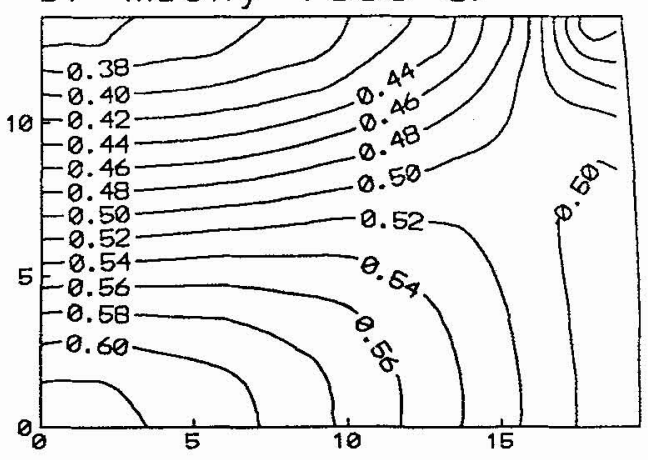

Fig.7. Calculated distributions of the effective strain for the solid stalte daformation in $450^{\circ} \mathrm{C}$ (a) and for the partly liquid state deformation in $550^{\circ} \mathrm{C}(\mathrm{b})$. 


\section{CONCLUSIONS}

Experimental investigation carried out for the 2024 alloy confirmed advantages of the partly liquid

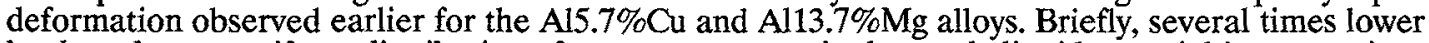
loads and more uniform distribution of stresses was seen in the partly liquid material in comparison with the deformation in the solid state. Theoretical analysis of the process showed, however, that generalization of the softening effect is a difficult problem. Comparison of the measured and calculated stress-strain curves for various alloys lead to a conclusion that the softening factor cannot be defined as a function of the volume fraction of the liquid phase only. It seems that other factors, such as chemical composition, should be also taken into consideration.

\section{ACKNOWLEDGEMENTS}

The financial assistance of the Polish Scientific Research Committee (grant no. 7 7402 92 03) is gratefully acknowledged.

\section{REFERENCES}

[1] FUKOKAS. and KIUCHI M., Proc. 15th MTDR Conf., Birmingham, 1974, Macmillan, London, $1975,423$.

[2] FUKOKAS. and KIUCHI M., Proc. 16th MTDR Conf., Manchester, 1975, Macmillan, London, $1976,451$.

[3] FLEMINGS M.C., Met. Trans. A, 22A (1991), 957.

[4] KIUCHI M. and SUGIYAMA S., Proc. 2nd ICTP, Adv. Techn. Plast., (ed), K. Lange, Stuttgart, $1987,753$.

[5] LAPKOWSKI W., J. Mech. Work. Techn., 18 (1989) 305.

[6] LAPKOWSKI W., PIETRZYK M. and SINCZAK J., Proc. 4th Int. Conf. METAL FORMING'92, eds, Pietrzyk M. and Kusiak J., Elsevier Science Publishers, Krakow, 1992, 481.

[7] LAPKOWSKI W., PIETRZYK M. and SINCZAK J., Proc. Conf. Adv. Eng. Plast. Appl. AEPA'92, ed., Lee W.B., Hong Kong, 1992, Elsevier Science Publishers, 1085.

[8] Lapkowski W., PhD thesis, AGH, Krakow, 1975.

[9] PIETRZYK M. and LENARD J.G., Proc 9th Int. Heat Transf. Conf., Jerusalem, 1990, 413.

[10] PIETRZYK M., Hutnik, 58 (1991) 63. 